\title{
Cerebral oxygen saturation monitoring in pediatric cardiopulmonary resuscitation patients in the emergency settings: A small descriptive study
}

\author{
Aykut Çağlar, Anıl Er, Emel Ulusoy, Fatma Akgül, Hale Çitlenbik, Durgül Yılmaz, \\ Murat Duman \\ Division of Pediatric Emergency Medicine, Department of Pediatrics, Dokuz Eylul University Faculty of Medicine, Izmir, \\ Turkey.E-mail: mduman@deu.edu.tr \\ Received: 27th February 2017, Accepted: 2nd April 2017
}

SUMMARY: Çağlar A, Er A, Ulusoy E, Akgül F, Çitlenbik H, Yılmaz D, Duman M. Cerebral oxygen saturation monitoring in pediatric cardiopulmonary resuscitation patients in the emergency settings: A small descriptive study. Turk J Pediatr 2017; 59: 642-647.

Near infrared spectroscopy (NIRS) is a new technology for monitoring cardiopulmonary resuscitation (CPR). The use of NIRS has advantages in monitoring cerebral oxygenation in cardiac arrest patients. The aim of this study was to describe cerebral regional oxygen saturation $\left(\mathrm{CrSO}_{2}\right)$ values in a small cohort of pediatric out-of-hospital cardiac arrest patients and to determine if there is an association with $\mathrm{CrSO}_{2}$ and return of spontaneous circulation (ROSC).

All the out-of-hospital cardiac arrest patients admitted to our pediatric emergency department were included in this prospective study. All patients were monitored through NIRS in addition to standard monitoring during CPR. All cerebral $\mathrm{rSO}_{2}$ measurements were obtained with an INVOS 5100C cerebral/somatic oximeter. Cardiopulmonary resuscitation was performed according to the Pediatric Advanced Life Support 2010 guidelines. The patients were classified as ROSC and non - ROSC. Ten patients were included in this study. The median age of patients was 40.0 (14.0-88.2) months. Three (30\%) of the 10 patients achieved sustained ROSC. Abrupt increase in cerebral regional oxygen saturation $\left(\mathrm{CrSO}_{2}\right)$ was observed in all 3 of these patients. Minimum values of the $\mathrm{CrSO}_{2}$ were significantly lower and the percentage of median time with $\mathrm{CrSO} 2$ under $30 \%$ of $\mathrm{CrSO}_{2}$ were significantly higher in the non - ROSC group $(p=0.02)$. Our study indicated that the patients in the non - ROSC group have lower minimum $\mathrm{CrSO}_{2}$ value. Additionally, abrupt increase of $\mathrm{CrSO}_{2}$ during CPR could be an indicator for ROSC.

Key words: cerebral oximetry, pediatric, cardiac arrest, regional cerebral oxygen saturation, near infrared spectroscopy.

In cardiac arrest (CA) patients, the primary goal is to maintain normal brain activity after cardiopulmonary resuscitation (CPR). In past decades, many enhancements have been developed for high quality CPR to achieve better neurologic outcomes. Current guidelines suggest the use of end tidal $\mathrm{CO}_{2}$ $\left(\mathrm{ETCO}_{2}\right)$ to determine return of spontaneous circulation (ROSC). Evidence concerning the use of capnography in pediatric CA patients is inadequate in contrast to adults. ${ }^{1,2}$ The main disadvantage of the capnography is the necessity of an advanced airway with an effective tidal volume, and there are also some limitations in situations including the blockage of endotracheal intubation tube via secretion or blood. ${ }^{3}$ Additionally, in patients who have long CPR periods, $\mathrm{ETCO}_{2}$ cannot be truly determinative due to pulmonary edema. ${ }^{4}$

This manuscript has been previously and partly presented as an oral presentation at the $13^{\text {th }}$ Congress of Pediatric Emergency and Intensive Care, and as a poster presentation at the $7^{\text {th }}$ European Pediatrics and Pediatric Surgery Congress. 
The near infrared spectroscopy (NIRS) device is a monitor that can measure oxygenation of tissue with infrared technology similar to the pulse oximetry. Pulse oximeter measures only oxyhemoglobin in pulsatile tissue whereas NIRS can measure the difference between oxyhemoglobin and deoxyhemoglobin levels 2-3 $\mathrm{cm}$ below the sensor applied to the forehead region. This measurement reflects regional oxygenation of arterial, venous and capillary tissues in the frontal lobe of the brain. More importantly, NIRS does not required arterial pulsation in contrast to the pulse oximeter. ${ }^{5}$
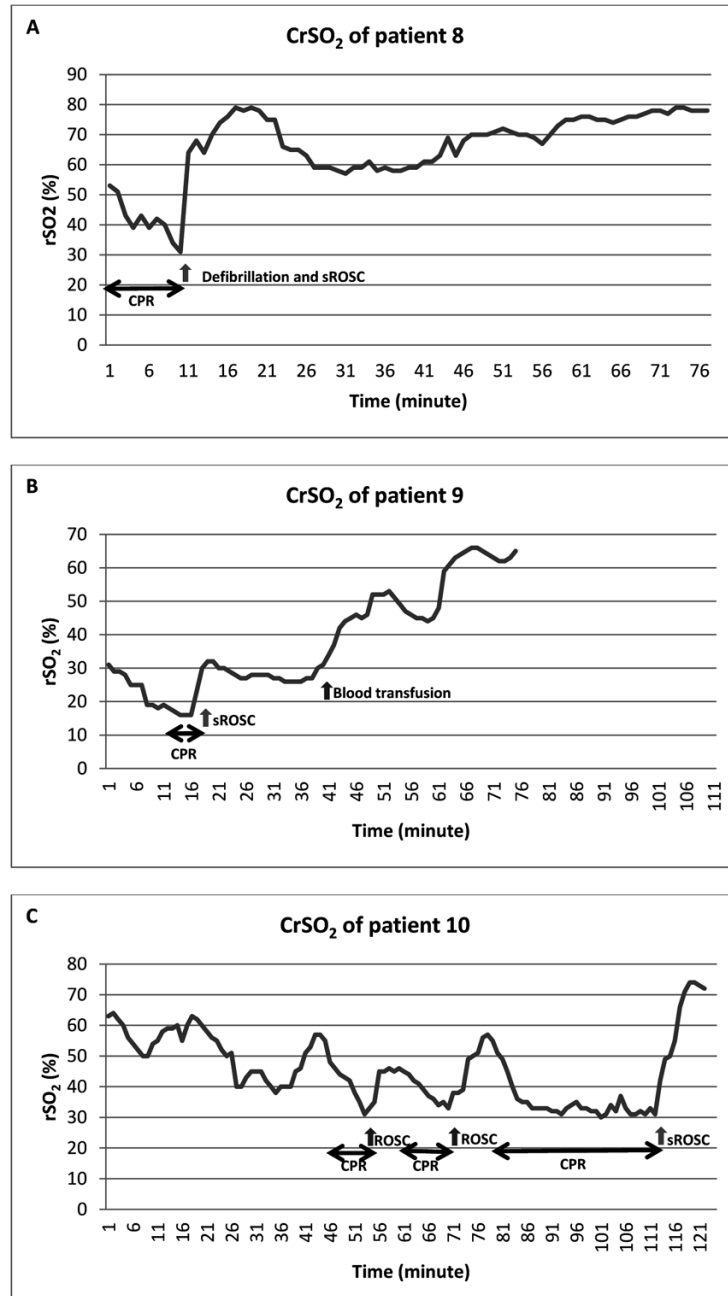

Fig.1. Abrupt increments of $\mathrm{CrSO}_{2}$ were observed in 3 patients. (A) The $\mathrm{CrSO}_{2}$ value of Patient 8 increased abruptly immediately after defibrillation. (B) Abrupt increments were observed in Patient 9 despite severe anemia. (C) In Patient 10, 3 CPR episodes were performed, but sustained ROSC was achieved with continued high levels of $\mathrm{CrSO}_{2}$.

ROSC: Return of spontaneous circulation, sROSC: Sustained ROSC
This difference is an advantage for NIRS use in CA patients. The use of NIRS in CA patients has increased in the few years prior to this study. The reports about whether the use of NIRS can be an indicator or not for ROSC are dominating the studies in the adult population ${ }^{6}$, but there are few studies that aim to determinate a cut of value of $\mathrm{CrsO}_{2}$ for futility of CPR. ${ }^{7-9}$ Pediatric studies about NIRS use in CA patients are limited to cardiac surgery patients. ${ }^{10}$ So we designed a descriptive study to investigate how useful monitoring $\mathrm{CrSO}_{2}$ is during CPR as a method for determination of ROSC or futility of CPR in pediatric out - of - hospital cardiac arrest (OHCA) patients in the emergency department (ED).

\section{Material and Methods}

\section{Setting and design}

We enrolled 17 OHCA patients in this prospective study between March 2014 and March 2016. All patients younger than 18 years of age with CA were included in this study. This study excluded patients with chronic cyanotic cardiac disease, pulmonary disease, frontal head trauma or intracranial injury.
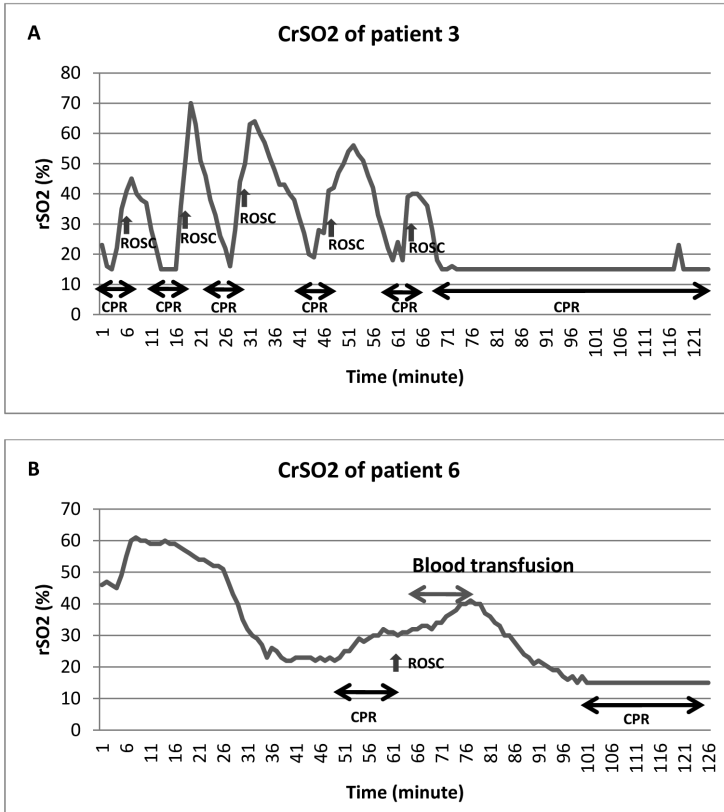

Fig. 2. Demonstration of sROSC is needed to continue high levels of $\mathrm{CrSO}_{2}$. (A) Patient 3 had 5 ROSC episodes after 2 minutes of CPR episodes. (B) Patient 6 achieved ROSC, but the $\mathrm{CrSO}_{2}$ value could not increase to higher levels even with a blood transfusion.

ROSC: Return of spontaneous circulation, sROSC: Sustained ROSC 
Table I. Patients' Characteristic Features and Prehospital Data.

\begin{tabular}{|c|c|c|c|c|c|c|c|}
\hline Patient & $\begin{array}{l}\text { Age } \\
(\mathrm{m})\end{array}$ & Sex & Etiology & $\begin{array}{l}\text { Body } \\
\text { temp }\end{array}$ & $\begin{array}{l}\text { Arrival time to } \\
\text { ED from scene } \\
\text { (min) }\end{array}$ & $\begin{array}{l}\text { Total duration } \\
\text { of CPR before } \\
\text { ED (min) }\end{array}$ & $\begin{array}{l}\text { Initial rhythm } \\
\text { in the ED }\end{array}$ \\
\hline $1^{\mathrm{ab}}$ & 2 & M & Heat stroke & 32.5 & 120 & 80 & Tachy \\
\hline $2^{\mathrm{b}}$ & 62 & M & Head trauma & 34.0 & 40 & 40 & Asy \\
\hline $3^{c}$ & 18 & M & Septic shock & 34.0 & 10 & 0 & Tachy \\
\hline 4 & 14 & $\mathrm{~F}$ & $\begin{array}{l}\text { Multiple } \\
\text { trauma }\end{array}$ & 34.2 & 8 & 8 & Asy \\
\hline $5^{\mathrm{ab}}$ & 14 & $\mathrm{~F}$ & Septic shock & 35.0 & 35 & 30 & Tachy \\
\hline $6^{\mathrm{ab}}$ & 64 & M & Drowning & 34.0 & 120 & 80 & Tachy \\
\hline $7^{b}$ & 67 & $\mathrm{~F}$ & Asphyxia & 36.0 & 75 & 75 & Asy \\
\hline 8 & 152 & $\mathrm{~F}$ & VT & 35.6 & 15 & 15 & VT \\
\hline $9^{a}$ & 17 & M & $\begin{array}{l}\text { Multiple } \\
\text { trauma }\end{array}$ & 35.0 & 15 & 10 & Tachy \\
\hline $10^{\mathrm{a}}$ & 158 & $\mathrm{~F}$ & Unknown & 34.8 & 10 & 2 & Tachy \\
\hline
\end{tabular}

a Five patients have achieved ROSC after CPR before admission to the ED.

b These patients had recurrent CPR episodes before admission to the ED.

Table II. Patients' CPR Characteristics, and Cerebral $\mathrm{rSO}_{2}$ Values in the ED.

\begin{tabular}{|c|c|c|c|c|c|c|c|c|c|c|}
\hline \multirow[t]{3}{*}{ Patient } & \multirow{3}{*}{$\begin{array}{l}\text { Initial } \\
\text { rhythm } \\
\text { when } \\
\text { CPR } \\
\text { started }\end{array}$} & \multirow{3}{*}{$\begin{array}{l}\text { Duration } \\
\text { of CPR } \\
\text { in the } \\
\text { ED } \\
(\text { min })\end{array}$} & \multirow{3}{*}{$\begin{array}{l}\text { CPR } \\
\text { episodes } \\
\text { in the } \\
\text { ED }\end{array}$} & \multirow[t]{3}{*}{ sROSC } & \multirow{3}{*}{$\begin{array}{l}\text { Hospital } \\
\text { discharge } \\
\text { status }\end{array}$} & \multicolumn{5}{|c|}{$\mathrm{CrSO}_{2}$ values } \\
\hline & & & & & & \multirow{2}{*}{$\begin{array}{l}\text { On } \\
\text { admission } \\
\text { to the ED }\end{array}$} & \multicolumn{4}{|c|}{$\mathrm{CrSO}_{2}$ during $\mathrm{CPR}$} \\
\hline & & & & & & & Initial & Lowest & Highest & Avg \\
\hline 1 & Brady & 45 & 1 & No & Death & 31 & 15 & 15 & 15 & 15.0 \\
\hline 2 & Asy & 42 & 1 & No & Death & 33 & 33 & 29 & 51 & 41.0 \\
\hline $3^{\mathrm{a}}$ & Brady & 57 & 6 & No & Death & 23 & 16 & 15 & 23 & 15.3 \\
\hline 4 & Asy & 45 & 1 & No & Death & 31 & 31 & 25 & 42 & 28.4 \\
\hline 5 & Brady & 30 & 1 & No & Death & 24 & 24 & 23 & 30 & 25.7 \\
\hline $6^{\mathrm{a}}$ & Brady & 52 & 2 & No & Death & 22 & 17 & 15 & 15 & 15.0 \\
\hline 7 & Asy & 45 & 1 & No & Death & 45 & 45 & 23 & 48 & 34.1 \\
\hline 8 & VT & 35 & 1 & Yes & Alive & 37 & 37 & 31 & 53 & 41.5 \\
\hline 9 & Brady & 4 & 1 & Yes & Death & 30 & 32 & 29 & 32 & 30.6 \\
\hline $10^{a}$ & Brady & 51 & 3 & Yes & Death & 46 & 48 & 30 & 57 & 38.4 \\
\hline
\end{tabular}

ROSC: Return of spontaneous circulation, sROSC: Sustain ROSC, ED: Emergency department, CPR: Cardiopulmonary resuscitation,Tachy: Tachycardia, Asy: Asystole, VT: Ventricular tachycardia, $\mathrm{CrSO}_{2}$ : Cerebral regional oxygen saturation, Avg: Average.

aThese patients had recurrent CPR episodes in the ED, the values shown in the table belong to the last episodes of the patients.

Consistent with the Pediatric Advanced Life Support 2010 guidelines, CPR was performed on all patients by pediatric emergency physicians and pediatric residents. All patients were monitored by nursing staff with a pulse oximeter and by electrocardiogram (ECG).
In addition, $\mathrm{ETCO}_{2}$ monitoring was used for patients with an advanced airway. The characteristic features related to CPR were recorded as such: initial rhythm on admission to the ED and at the start of the CPR, elapsed time until admission to the ED, total duration 
Table III. Patients' Laboratory Data.

\begin{tabular}{lllllll}
\hline Patient & $\mathrm{Hb}$ & $\mathrm{pH}$ & $\mathrm{pCO}_{2}$ & $\mathrm{HCO}_{3}$ & $\mathrm{BE}$ & Lactate \\
\hline 1 & 9.1 & 7.1 & 56.5 & 16.8 & -8.1 & 13.8 \\
3 & 12.0 & 6.8 & 66.6 & 7.7 & -20.8 & 17.0 \\
5 & 12.1 & 7.1 & 43.4 & 15.0 & -11.2 & 0.8 \\
6 & 5.3 & 6.6 & 58.7 & 5.1 & -25.7 & 18.0 \\
8 & 14.6 & 7.0 & 63.1 & 10.9 & -14.4 & 7.2 \\
9 & 2.7 & 6.9 & 51.5 & 8.6 & -20.2 & 7.9 \\
10 & 15.0 & 7.0 & 72.4 & 11.6 & -12.2 & 7.2 \\
\hline
\end{tabular}

Blood test can be obtained in 7 patients. The median (IQR) timing of drawing blood was 5.0 minutes from admission to the $\operatorname{ED}(5.0-7.0)$.

of CPR in the ED and before admission to the $\mathrm{ED}, \mathrm{ROSC}$ and sustained ROSC if achieved. ROSC was defined as the presence of arterial pulsation after CPR. If ROSC continued longer than 20 minutes, a terminology of sustained ROSC was used.

Near-infrared spectroscopy probe was administered using adhesive strips to the right and left frontal area by a paramedic. All cerebral $\mathrm{rSO}_{2}$ measurements were obtained with an INVOS 5100C cerebral/somatic oximeter (Covidien, Mansfield, MA, USA). Cerebral monitoring was continued until CPR was terminated or until patients who achieved sustained ROSC were transferred to the pediatric intensive care unit.

This study was approved by the Dokuz Eylul University Faculty of Medicine Clinical Research Ethics Committee. Financial assistance has not been received for this study

\section{Statistical method}

Statistical analysis was performed using SPSS Software 16.0. If the numerical data fit the normal distribution, mean \pm standard deviation were calculated, if the numerical data did not fit a normal distribution median, the interquartile range (IQR) 25-75 percentile was calculated. The Mann-Whitney U test was used to compare the variables that did not fit normal distribution. The definitive chi-square test was used for the numerical variables. Statistical significance was accepted as p < 0.05 for all tests.

\section{Results}

Seventeen OHCA patients were originally included in this study. Seven patients were excluded: 3 due to technical problems, 2 who had congenital cyanotic cardiac disease, and 2 who had frontal hematoma due to trauma. A total of 10 patients were included in the study. The median (IQR) age of patients was 40.0 (14.0-88.2) months. Five of the 10 patients were boys. The characteristics of the patients are summarized in Table I and II. Cardiopulmonary resuscitation was performed in 9 of the 10 patients by the physicians of the emergency medical transport services prior to arrival at the ED. In 5 of the 9 patients, ROSC was restored and they had tachycardia on admission and CPR was started again when their heart rates decreased under 60/ min. The median time of the duration of CPR before the arrival to the ED and the elapsed time until admission to the ED were 22.5 (6.5-76.2) and 25.0 (10.0-86.2) minutes, respectively. The median duration of CPR in the ED was 45.0 (33.7-51.2) minutes. All patients were monitored with a pulse oximeter and ECG. ETCO 2 measurement was obtained in only 3 patients, as 3 patients had pulmonary hemorrhages. Four patients did not have an advanced airway for avoiding interruption of chest compression because ventilation via bag valve mask was provided effectively. Blood specimens were obtained in 7 of 10 the patients. Laboratory parameters of the patients are summarized in Table III. Three $(30 \%)$ of 10 patients achieved sustained ROSC. Abrupt increases in cerebral regional oxygen saturation $\left(\mathrm{CrSO}_{2}\right)$ were observed in these 3 patients (Fig 1). After ROSC, the average $\mathrm{CrSO} 2$ of the patients (patients 8,9 , and 10) were $69.3 \%, 44.6 \%$, and $68.8 \%$; respectively. Patient 9 had severe anemia due to splenic injury, his increments of $\mathrm{CrSO}_{2}$ continued to 
Table IV. Comparison of Groups with and without ROSC.

\begin{tabular}{llll}
\hline Parameters & ROSC & & $\mathrm{p}^{\mathrm{b}}$ \\
& Yes $(\mathrm{n}=3)$ & $\mathrm{No}(\mathrm{n}=7)$ & \\
\hline Percentage of median time with CrSO2 under 30\% & $0.0(0.0-25.0)^{\mathrm{b}}$ & $100(27-100)$ & 0.02 \\
$\mathrm{CrSO}_{2}$ values on admission & $37.0(30.0-46.0)$ & $31.0(23.0-33.0)$ & 0.20 \\
$\mathrm{Initial} \mathrm{CrSO} 2$ during CPR $^{\text {Median } \mathrm{CrSO}_{2} \text { in the last } 5 \text { minutes }}$ & $24.0(16.0-33.0)$ & $37.0(32.0-48.0)$ & 0.08 \\
${\text { Minimum } \mathrm{CrSO}_{2} \text { during CPR* }}^{*}$ & $31.5(29.5-31.5)$ & $26.2(15.0-30.3)$ & 0.08 \\
Maximum $\mathrm{CrSO}_{2}$ during CPR & $30.0( \pm 1.0)$ & $20.7( \pm 5.7)$ & 0.02 \\
Average $\mathrm{CrSO}_{2}$ during CPR & $53.0(32.0-57.0)$ & $30.0(15.0-48.0)$ & 0.08 \\
Duration of resuscitation in the ED & $38.4(30.6-41.5)$ & $25.7(15.0-34.1)$ & 0.08 \\
Hemoglobin $(\mathrm{g} / \mathrm{dl})$ & $35.0(4.0-51.0)$ & $45.0(42.0-52.0)$ & 0.29 \\
Body Temperature $\left({ }^{\circ} \mathrm{C}\right)^{*}$ & $14.6(2.7-15.0)$ & $10.5(6.2-12.0)$ & 0.48 \\
\hline
\end{tabular}

Values are median (interquartile range)

*Values are mean $( \pm S D)$

${ }^{a}$ value is median ( $\min -\max$ )

bMann-Whitney $\mathrm{U}$ test was used to compare the 2 groups.

increase markedly after transfusion of red blood cells. Comparisons between the patients with and without ROSC are summarized in Table IV. Minimum values of $\mathrm{CrSO}_{2}$ were significantly higher and the percentage of median time with $\mathrm{CrSO} 2$ under $30 \%$ of $\mathrm{CrSO}_{2}$ were significantly lower in the ROSC group $(\mathrm{p}=0.02)$ Patients 9 and 10 died in the pediatric intensive care unit and patient 8 survived with mild neurologic deficits (cerebral performance category scale 1 ).

Informed consent was obtained from the patients' parents.

\section{Discussion}

In all pediatric OHCA patients, the primary goal is to maintain normal cerebral function after ROSC by high quality CPR. In the current study, we aimed to determine whether using NIRS is a useful method for monitoring CPR in ED settings. There are controversial studies in the literature about monitoring CPR with cerebral $\mathrm{rSO}_{2}$. To our knowledge, this is the first prospective cohort study of pediatric OHCA patients in the literature. Although Newman et al. ${ }^{11}$ found that $\mathrm{CrSO}_{2}$ had no effect on CPR, some studies with opposing findings have been published recently. $8,12-14$ Newman et al. ${ }^{11}$ reported that cerebral oxygenation is rarely detectable in OHCA patients and they concluded that this result is due to a longer time from the arrest event to the initial measurements. Another study enrolling 33
OHCA patients with a $\mathrm{CrSO}_{2}$ value of $15 \%$ reported that all 33 patients died, and the authors indicated that the data might predict the futility of CPR. In our study, 2 patients with the longest CPR period before arrival to the ED had no change of $\mathrm{CrSO}_{2}$ during CPR. This finding was consistent with previous studies. ${ }^{9,11}$

There is no absolute threshold for $\mathrm{CrSO}_{2}$ value to determine the futility of CPR. Fukuda et al. ${ }^{7}$ reported that lower $\mathrm{CrSO}_{2}$ values may be a predictor for non-ROSC. Also, in another study, none of the patients with $\mathrm{CrSO}_{2}$ below $30 \%$ achieved ROSC. ${ }^{8}$ In a large multicenter study with adult patients which was reported by Parnia et al. ${ }^{15}$, while negative predictive value for prediction of ROSC was found $100 \%$ in values of $\mathrm{CrSO}_{2}$ greater than $25 \%$, whereas positive predictive value was found $93 \%$ for the prediction of ROSC in values of $\mathrm{CrSO}_{2}$ greater than $65 \%$. In our study, 3 of 10 patients achieved sustained ROSC. We found that the lowest $\mathrm{CrSO}_{2}$ and percentage of median time with $\mathrm{CrSO} 2$ under $30 \%$ were statistically different in the ROSC group, consistent with previous reports. ${ }^{7,15}$ Although a few studies reported that higher mean or median $\mathrm{CrSO}_{2}$ values might predict ROSC, we did not detect any difference for median and higher $\mathrm{CrSO}_{2}$ values between the ROSC and non-ROSC groups. We attributed this result to the limited number of patients and the long CPR durations 
of patients before arrival to the ED.

Abrupt increase of $\mathrm{CrSO}_{2}$ after ROSC have been documented in recently published studies. ${ }^{11-16}$ Parnia et al. ${ }^{12}$ reported that higher $\mathrm{CrSO}_{2}$ value in the last 5 minutes is more important than abrupt increase for prediction of sustained ROSC. Also in a large series study by the same author, the mean $\mathrm{CrSO}_{2}$ value in the last 5 minutes was highlighted as a major predictive factor for ROSC 15 . In our study, ROSC occurred in 5 patients, 3 of whom had recurrent CPR episodes. We observed sustained ROSC only in 3 of 5 patients with continued high levels of $\mathrm{CrSO}_{2}$ after ROSC. This data was consistent with our results. However, we found that there was not a statistically significant difference between groups for the median $\mathrm{CrSO} 2$ value in the last 5 minutes but we thought that these result was related with our limited patient number. The major limitation of this study was the small number of patients sampled. In addition, all patients had different lengths of time between the performing time between cardiac arrest and the initiation of NIRS measurement. Further studies are warranted to clarify whether there is role of $\mathrm{CrSO}_{2}$ in pediatric CPR.

In conclusion, the main result of this small descriptive study is that minimum $\mathrm{CrSO}_{2}$ value is lower in the non - ROSC patient group. And also, abrupt increase of $\mathrm{CrSO}_{2}$ during CPR can be an indicator for ROSC, but ongoing high levels of $\mathrm{CrSO}_{2}$ values should be maintained for sustained ROSC. Further evaluation of NIRS during pediatric CPR may be helpful to reach more accurate results.

\section{REFERENCES}

1. Maconochie IK, de Caen AR, Aickin R, et al. Part 6: Pediatric basic life support and pediatric advanced life support: 2015 International Consensus on Cardiopulmonary Resuscitation and Emergency Cardiovascular Care Science with Treatment Recommendations. Resuscitation 2015; 95 :e147-e168.

2. Link MS, Berkow LC, Kudenchuk PJ, et al. Part 7: Adult Advanced Cardiovascular Life Support: 2015 American Heart Association Guidelines Update for Cardiopulmonary Resuscitation and Emergency Cardiovascular Care. Circulation 2015; 132: S444-S464.

3. Kodali BS, Urman RD. Capnography during cardiopulmonary resuscitation: Current evidence and future directions. J Emerg Trauma Shock 2014; 7: 332-340.
4. Peberdy MA, Callaway CW, Neumar RW, et al. Part 9: Post-Cardiac Arrest Care: 2010 American Heart Association Guidelines for Cardiopulmonary Resuscitation and Emergency Cardiovascular Care. Circulation 2010; 122: S768-S786.

5. Marin T, Moore J. Understanding near-infrared spectroscopy. Advances in neonatal care : official journal of the National Association of Neonatal Nurses 2011; 11: 382-388.

6. Sanfilippo F, Serena G, Corredor C, et al. Cerebral oximetry and return of spontaneous circulation after cardiac arrest: A systematic review and meta-analysis. Resuscitation 2015; 94: 67-72.

7. Fukuda T, Ohashi N, Nishida M, et al. Application of cerebral oxygen saturation to prediction of the futility of resuscitation for out-of-hospital cardiopulmonary arrest patients: a single-center, prospective, observational study: can cerebral regional oxygen saturation predict the futility of CPR? Am J Emerg Med 2014; 32: 747751.

8. Ahn A, Nasir A, Malik H, D’Orazi F, Parnia S. A pilot study examining the role of regional cerebral oxygen saturation monitoring as a marker of return of spontaneous circulation in shockable (VF/VT) and non-shockable (PEA/Asystole) causes of cardiac arrest. Resuscitation 2013; 84: 1713-1716.

9. Ito N, Nanto S, Nagao K, Hatanaka T, Kai T. Regional cerebral oxygen saturation predicts poor neurological outcome in patients with out-of-hospital cardiac arrest. Resuscitation 2010; 81:1736-1737.

10. Abramo T, Aggarwal N, Kane I, Crossman K, Meredith M. Cerebral oximetry and cerebral blood flow monitoring in 2 pediatric survivors with out-ofhospital cardiac arrest. Am J Emerg Med 2014; 32: 394 e5- e10.

11. Newman DH, Callaway CW, Greenwald IB, Freed J. Cerebral oximetry in out-of-hospital cardiac arrest: standard CPR rarely provides detectable hemoglobinoxygen saturation to the frontal cortex. Resuscitation 2004; 63: 189-194.

12. Parnia S, Nasir A, Shah C, et al. A feasibility study evaluating the role of cerebral oximetry in predicting return of spontaneous circulation in cardiac arrest. Resuscitation 2012; 83: 982-985.

13. Kamarainen A, Sainio M, Olkkola KT, et al. Quality controlled manual chest compressions and cerebral oxygenation during in-hospital cardiac arrest. Resuscitation 2012; 83: 138-142.

14. Schewe JC, Thudium MO, Kappler J, et al. Monitoring of cerebral oxygen saturation during resuscitation in out-of-hospital cardiac arrest: a feasibility study in a physician staffed emergency medical system. Scand J Trauma Resusc Emerg Med 2014; 22: 58.

15. Parnia S, Yang J, Nguyen R, et al. Cerebral oximetry during cardiac arrest: A multicenter study of neurologic outcomes and survival. Crit Care Med 2016; 44: 16631674.

16. Meex I, De Deyne C, Dens J, et al. Feasibility of absolute cerebral tissue oxygen saturation during cardiopulmonary resuscitation. Crit Care 2013; 17: R36. 